\title{
Synthesis of Photochromic Benzodixanthene Analogues with 2- Pyridyl Group and Formation of Monolayers on Water Surface
}

\author{
Tomohiro Watanabe, ${ }^{\text {a) }}$ Gen Yamakawa, ${ }^{\text {a) }}$ Sumio Tokita ${ }^{a}{ }^{*}$ and Hiroo Nakahara ${ }^{b)}$ \\ a) Department of Applied Chemistry, Faculty of Engineering, Saitama University, \\ 255 Shimo-Ohkubo, Urawa, Saitama, 338 Japan \\ b) Department of Chemistry, Faculty of Science, Saitama University, \\ 255 Shimo-Ohkubo, Urawa, Saitama, 338 Japan
}

\begin{abstract}
Nitrogen analogues of benzo[1, 2,3-kl:4,5,6-k'l']dixanathene with 2-pyridyl group were synthesized from 1,5-dichloroanthraquinone in six steps. After quaternization with iodoalkane, photochromic properties were investigated in ethanol or in toluene. The compound having a decyl group formed monolayer on water surface at $10{ }^{\circ} \mathrm{C}$.
\end{abstract}

Keywords: benzodixanthene, quaternization, photochromism, monolayer

\section{Introduction}

Benzo[1, 2, 3-kl : 4, 5, 6-k'l']dixanthene (1a) and its analogues are well known as typical polycondensed aromatic compounds having photochromic properties. [1] Molecular design of analogues of $1 \mathrm{a}$ and its isomer $3 \mathbf{a}$ were performed to predict absorption maxima of these compounds. [2] The relation between the coefficients of highest occupied molecular orbitals of 1a or 3a and the conformation of their endoperoxide was investigated by semiempirical molecular orbital method and $\mathrm{X}$-ray crystallo-graphic analysis. [3]

Photochromic properties of monolayers on water surface have been widely studied. Mixtures of the alkylsubstituted thioindigo dyes and tripalmitine were found to form monomolecular films and to control the photochromic reaction in the Langmuir - Blodgett films. [4] The Langmuir - Blodgett films of spiropyrane derivatives have been extensively studied.[5] Seki et al. have reported the photochemical behavior of poly(vinyl alcohol)s having an azobenzene side chain and azobenzene mono- layers.[6] The rates and the surface pressure dependence of the photochromic reaction of spirobenzoselenazopyrans with long chains in monolayers on water surface has been investigated.[7]

However, any derivative of 1a or $3 \mathrm{a}$ has not been reported to construct monolayers on water surface. In the present work, we synthesized several novel photochromic compounds (1c 1g) containing 2-pyridyl group. The solubilites and the photochromic properties of these compounds were studied. Furthermore, the monolayers spread from their benzene solution were preliminarily examined.

\section{Method}

Solvents and reagents were purified using literature method. Thin-layer chromatography (TLC) was performed on plastic or glass plate $(10 \times 5 \mathrm{~cm})$ coated with Merck 5735 silica gel 60F. Column chromatography was performed using Wakogel C-300 (200-300 mesh, Wako Pure Chemical Industries, Ltd.). Melting points were determined with a Buch melting point 


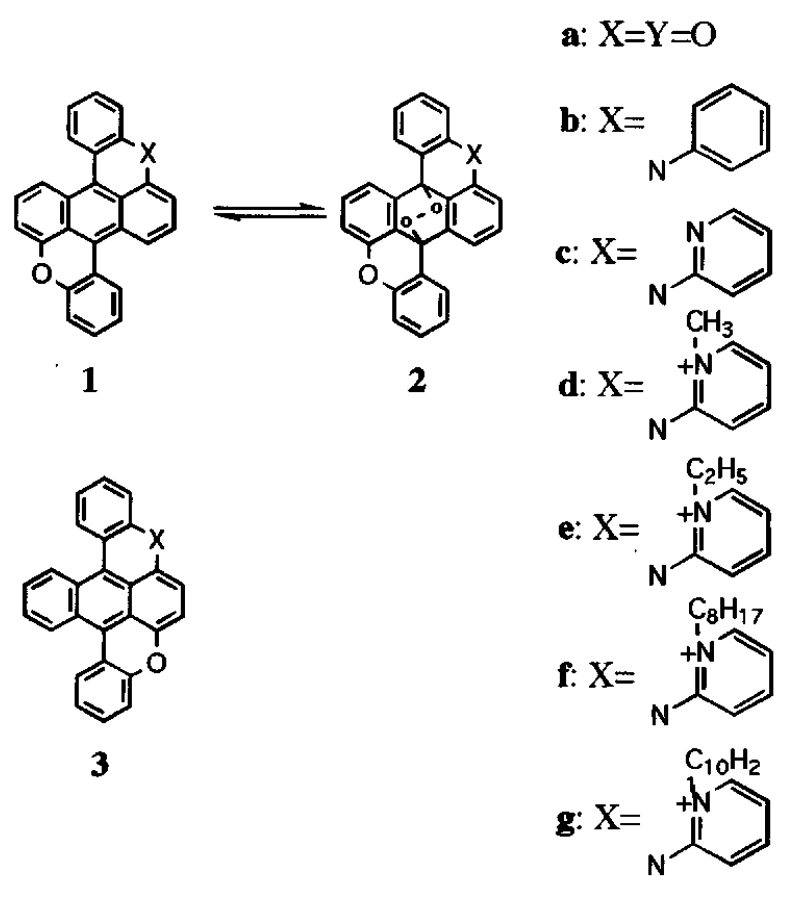

apparatus and were uncorrected. UV-VIS spectra were recorded on a Shimadzu UV-2100 spectrophotometer. IR spectra were obtained on JASCO A-302 and Perkin-Elmer 1600 FT-IR. ${ }^{1}$ H NMR spectra were recorded on Bruker AM-400 spectrometer, using tetramethylsilane as an internal standard.

\subsection{Synthetic routes}

Synthetic routes to compounds $1 \mathrm{c}-\mathbf{1 g}$ are shown in Scheme 1.

\subsection{Computational method}

Geometries are initially optimized by molecular mechanics [9] with CAChe.[10] After further optimization by AM1 procedure [11] absorption maxima were calculated using INDO/S.[12]

\subsection{Formation of monolayers on water surface}

Monolayers were spread from the benzene solution on the distilled water surface and the surface pressure - area $(\pi-A)$ isotherms were measured by using a Lauda film balance.

\section{Results and Discussion}

\subsection{Absorption maxima}

The electronic spectrum of $1 \mathbf{b}$ showed a bathochromic shift compared with that of 1a.[2] The introduction of more electron-donating atom $-\mathrm{N}<$ instead of $-\mathrm{O}$ - was explained to cause a

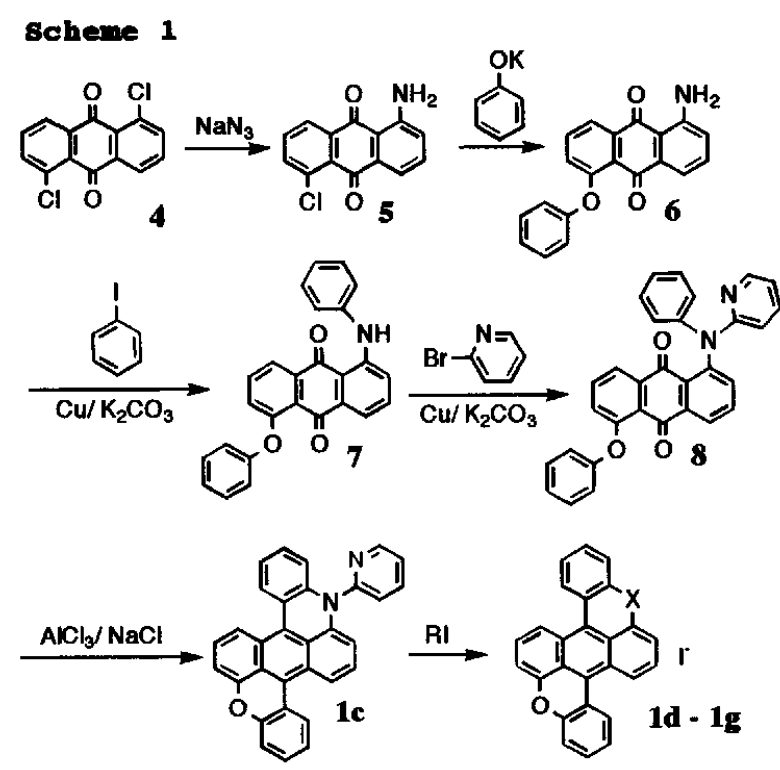

bathochromic shift. [8]

The absorption maximum of 1c shifted to slightly shorter wavelength than that of $\mathbf{1 b}$. The electron-withdrawing effect of 2-pyridyl group in 1c weaken the electron-donating effect of the nitrogen atom $-\mathrm{N}<$ of $\mathbf{1 b}$ to give hypsochromic shift.

The absorption maxima of quaternary compounds 1d - 1g shifted to shorter wavelengths than those of 1b - 1c. These tendencies indicate that the electron-withdrawing effect of the cation $=\mathrm{N}^{+}<$is much stronger than that of the nitrogen atom $-\mathrm{N}=$ of 2-pyridyl group.

Table 1. First absorption maxima of $1 \mathrm{a}$ and its

\begin{tabular}{cccc}
\multicolumn{3}{c}{ analogues } \\
\cline { 1 - 2 } & \multicolumn{2}{c}{$\lambda$ max, obs $/ \mathbf{n m}$} & \\
\cline { 2 - 3 } & toluene & ethanol & $\lambda$ max, calc $/ \mathbf{n m}$ \\
\hline 1a & 541 & & 462 \\
1b & 589 & & 483 \\
1c & 582 & 574 & 482 \\
1d & & 547 & 472 \\
1e & & 546 & 471 \\
1f & 558 & 546 & 472 \\
1g & 557 & 540 & 470 \\
\hline
\end{tabular}

The correlation between calculated and observed wavelengths of $1 \mathrm{a}-\mathbf{1 g}$ is shown in Fig. 1. The calculated wavelengths are shorter than observed ones, however, the correlation between 
them may be reasonable, judging from the fittings of correlation lines. In many cases, absorption maxima calculated by ZINDO approximation have tendency to give similar results.[13]

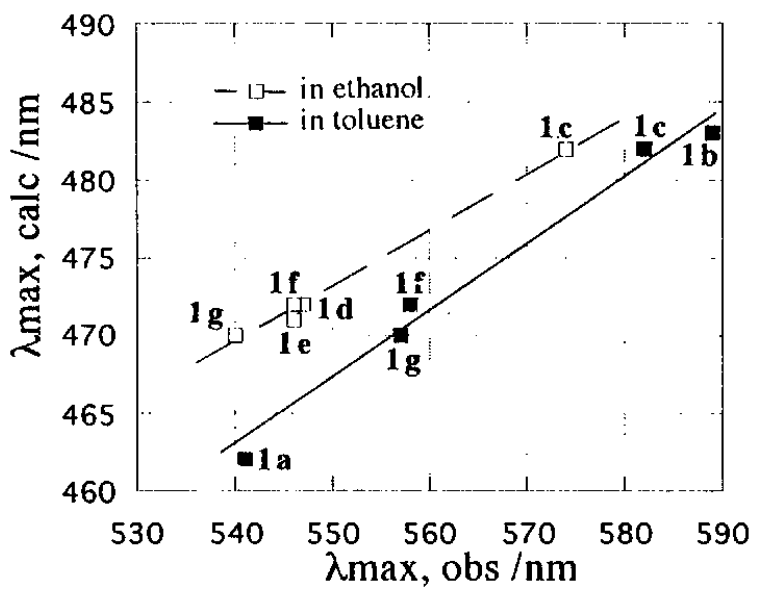

Fig. 1 Correlation between calculated wavelengths (in vacuum) and observed ones (in toluene or in ethanol).

\section{$3.2{ }^{1} \mathrm{H} \mathrm{NMR}$}

A ${ }^{1} \mathrm{H}$ NMR analysis of benzodixanthene analogues gave a similar explanation to the above discussion ( $\S 3.1$ ) concerning the electron-donating properties of nitrogen atom in the molecular framework.

The signal of $\mathrm{H}_{l}$ in $\mathbf{1 b}$ appears upfield from those of bay protons such as phenanthrenes or benzophenanthrenes. Similarly, the signal of $\mathrm{H}_{c}$ in $1 \mathrm{~b}$ appears upfield from those of ordinary aromatic protons reflecting the electrondonating effect of nitrogen atom $-\mathrm{N}<$.

The chemical shifts of $\mathrm{H}_{a}$ and $\mathrm{H}_{n}$ are observed at the higher field than $\mathrm{H}_{l}$ or $\mathrm{H}_{c}$ depending on the electron-donating effect of the nitrogen atom $-\mathrm{N}<$ of the molecular framework together with the shielding effect of aryl (phenyl or pyridyl) group which lies almost perpendicular to the average plane of mother structure (benzodixanthene analogue).

Reflecting the perpendicular geometry of phenyl (or pyridyl) ring to the mother structure, the ${ }^{1} \mathrm{H}$ NMR signals of $1 \mathrm{c}$ are similar to those of 1b. On the other hand, the chemical shifts of $1 f$ (or 1g) are observed at lower field than those of 1b or 1c. These results may be ascribed to the stronger electron-withdrawing ability of $=\mathrm{N}^{+}<$ than that of $-\mathrm{N}=$ in 2-pyridyl group.
To say a long story short, the observed electron-withdrawing effect of 2-pyridyl group is small, however, that of quaternary atom is large in ${ }^{1} \mathrm{H}$ NMR, coincided with the observed tendencies in UV-VIS spectra.

Table 2. ${ }^{1} \mathrm{H}$ NMR chemical shifts $(\delta / \mathrm{ppm})$

\begin{tabular}{cccccc}
\hline & $\mathrm{Z}$ & $\mathrm{H}_{l}$ & $\mathrm{H}_{c}$ & $\mathrm{H}_{a}$ & $\mathrm{H}_{n}$ \\
\hline $1 \mathrm{~b}$ & $\mathrm{CH}$ & 7.80 & 7.04 & 6.28 & 5.78 \\
$\mathrm{1f}$ & $\mathrm{N}$ & 7.82 & 7.08 & 6.17 & 5.72 \\
$1 \mathrm{fg}{ }^{+}{ }^{+}-\mathrm{C}_{8} \mathrm{H}_{17}$ & 8.19 & 7.29 & 6.45 & 5.99 \\
${ }^{+}-\mathrm{C}_{10} \mathrm{H}_{21}$ & 8.17 & 7.27 & 6.44 & 6.00 \\
\hline
\end{tabular}

\subsection{Photochromic properties}

Spectral changes accompanied with the photooxidation reaction of $1 \mathrm{c}$ in toluene under irradiation of $582 \mathrm{~nm}$ light are shown in Fig. 2. The peak heights of absorption maxima at $\mathbf{5 8 2}$ $\mathrm{nm}, 546 \mathrm{~nm}$, and $424 \mathrm{~nm}$ of $1 \mathrm{c}$ are decreased, and the peak height at $340 \mathrm{~nm}$ (ascribed to endoperoxide 2c) is increased.

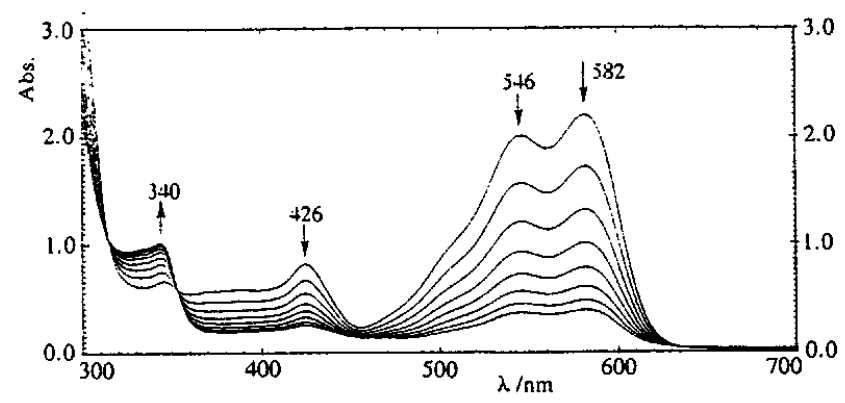

Fig. 2. Spectral changes of $1 \mathrm{c}$ in toluene under photooxidation 
The endoperoxide $2 \mathrm{c}$ regenerated $1 \mathrm{c}$ upon heating at $110^{\circ} \mathrm{C}$. Analogous compounds 1d $1 \mathrm{~g}$ showed similar spectral changes with irradiation of visible light in toluene solutions.

\subsection{Solvent effect}

$1 \mathrm{a}$ and $1 \mathrm{~b}$ were not soluble in polar solvent. On the other hand, 1d and 1e were soluble in water or ethanol. In ethanol, photooxidation of 1d or 1e occurred to give its endoperoxide $2 d$ or $2 e$, respectively. Heating the ethanol solution of endoperoxide over $78{ }^{\circ} \mathrm{C}$ regenerated $1 \mathrm{~d}$ or $1 \mathrm{e}$. In water, however, the similar photochromic reactions of 1d or 1e were not observed.

If and $1 \mathrm{~g}$ were soluble in ethanol or toluene. The photochromic reactions were observed in these solvent.

Absorption maxima of $1 \mathrm{f}$ (or $\mathbf{1 g}$ ) in ethanol shifted to shorter wavelengths than those in toluene, respectively. As the polarization around $-\mathrm{N}^{+}=$may be more facilitated in water than in ethanol, the 2-pyridinium group in water will withdraw the electron move strongly than in ethanol.

\subsection{Monolayers on water surface}

We have investigated the possibility of monolayer formations of $\mathbf{1 f}$ and $\mathbf{1 g}$ on the water surface. The surface pressure - area $(\pi-A)$ isotherms for the monolayers of each compound under the dark condition are shown in Fig. 3. The photochromic compound $1 \mathrm{~g}$ with decyl chain at $10{ }^{\circ} \mathrm{C}$ forms the condensed monolayer with a limiting area of $30 \AA^{2} /$ molecule. In this case, it is considered that $\pi$-electron systems of the molecular frameworks of $1 \mathrm{~g}$ stand side by side.

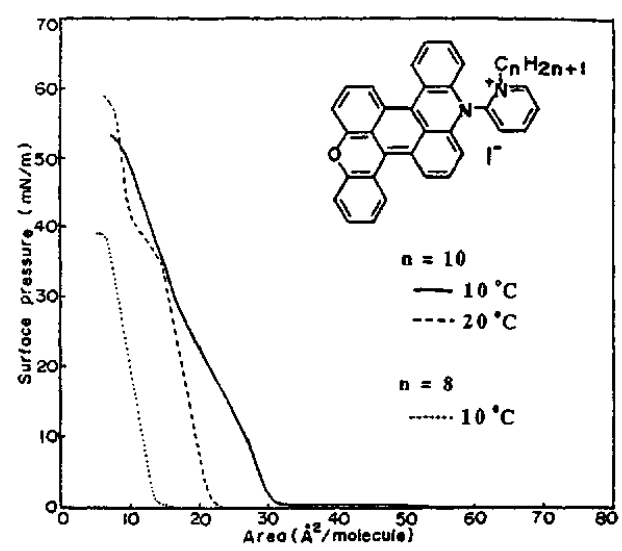

Fig. 3. Surface pressure - area isotherms of $1 f$ and $1 \mathrm{~g}$ under dark condition.
The C-N bond between nitrogen atom of the molecular framework and carbon atom of 2pyridyl group is fairly free rotation, therefore the alkyl chain will be nearly perpendicular to the water surface.

\section{Experimental}

1-amino-5-chloroanthraquinone (5).

Compound 5 was prepared as described in the reference. [14] Red needles (from acetone) in $17 \%$ yield, $\mathrm{mp} 198-210{ }^{\circ} \mathrm{C} ; \operatorname{IR}\left(\mathrm{cm}^{-1} / \mathrm{KBr}\right)$ $3428,3320,1628,1555$ and $1271 ;{ }^{1} \mathrm{H}$ NMR ( $\mathrm{CDCl}_{3}$ /TMS, $\left.\delta \mathrm{ppm}\right) 6.82(\mathrm{br}, 2 \mathrm{H}, \mathrm{NH}), 6.96$ (dd, $1 \mathrm{H}), 7.48(\mathrm{t}, 1 \mathrm{H}), 7.58-7.67(\mathrm{~m}, 2 \mathrm{H}), 7.74$ (dd, 1H) and $8.31(\mathrm{dd}, 1 \mathrm{H})$; UV-VIS (nm in ethanol) 478 and 312 .

1-amino-5-phenoxyanthraquinone (6). A mixture of 1-amino-5-chloroanthraquinone 5 $(1.00 \mathrm{~g}, 3.87 \mathrm{mmol})$, potassium phenoxide $(3.00$ $\mathrm{g}, 20.3 \mathrm{mmol})$, pyridine $(12 \mathrm{ml})$ was heated under reflux at $105{ }^{\circ} \mathrm{C}$ for $4 \mathrm{~h}$ under argon atmosphere. The product was extracted with chloroform, pyridine was removed by $1 \%$ hydrochloric acid. The solvent was evaporated under reduced pressure. The residue was purified by column chromatography (toluene /silica gel). Recrystallization from toluene afforded 6 (546 mg, $1.72 \mathrm{mmol}, 45 \%$ ). Red needles, mp $197-200{ }^{\circ} \mathrm{C} ; \mathrm{IR}\left(\mathrm{cm}^{-1} / \mathrm{KBr}\right) 3428,1663,1614$ and $1272 ;{ }^{1} \mathrm{H} \mathrm{NMR}\left(\mathrm{CDCl}_{3} / \mathrm{TMS}, \delta \mathrm{ppm}\right) 6.82$ (br, 2H, NH), 6.93 (dd, 1H), 7.04 (dd, 2H), 7.11$7.25(\mathrm{~m}, 2 \mathrm{H}), 7.34-7.46(\mathrm{~m}, 2 \mathrm{H}), 7.44(\mathrm{t}, 1 \mathrm{H})$, $7.56(\mathrm{dd}, 1 \mathrm{H}), 7.65(\mathrm{t}, 1 \mathrm{H})$ and $8.13(\mathrm{dd}, 1 \mathrm{H})$; UV-VIS (nm in ethanol) 480.

1-anilino-5-phenoxyanthraquinone (7). A mixture of $6(1.00 \mathrm{~g}, 3.15 \mathrm{mmol})$, iodobenzene (700 mg, $3.43 \mathrm{mmol})$, copper powder $(240 \mathrm{mg}$, $3.78 \mathrm{mmol}$ ), anhydrous potassium carbonate (407 $\mathrm{mg}, 4.10 \mathrm{mmol}$ ), and bromobenzene (25 $\mathrm{ml}$ ) was heated under reflux at $145^{\circ} \mathrm{C}$ for $7 \mathrm{~h}$ under argon atmosphere. Bromobenzene and iodobenzene were removed by steam distillation, the copper was filtered with chloroform under heating. The solvent was evaporated under reduced pressure. The residue was purified by column chromatography (toluene/silica gel). Recrystallization from toluene afforded 7 ( $1.01 \mathrm{~g}, 2.27 \mathrm{mmol}, 88 \%$ ). Purple needles, $\mathrm{mp}$ 187-189 ${ }^{\circ} \mathrm{C} ; \mathrm{IR}\left(\mathrm{cm}^{-1} / \mathrm{KBr}\right) 3467,1594,1516$ and $1272 ;{ }^{1} \mathrm{H} \mathrm{NMR}\left(\mathrm{CDCl}_{3} / \mathrm{TMS}, \delta \mathrm{ppm}\right) 7.06$ 
(dd, 1H), 7.13-7.21 (m, 2H), 7.31-7.49 (m, $10 \mathrm{H}), 7.58-7.71(\mathrm{~m}, 2 \mathrm{H}), 8.16(\mathrm{dd}, 1 \mathrm{H})$ and 11.27 (s, 1H, NH); UV-VIS (nm in ethanol) 503.

1 - ( 1 -phen y - 2 - bipy ridy la mino) - 5 phenoxyanthraquinone (8). A mixture of 7 (500 $\mathrm{mg}, 1.28 \mathrm{mmol}), 2$-bromopyridine $(11.0 \mathrm{~g}$, $69.7 \mathrm{mmol}$ ), copper powder $(300 \mathrm{mg}, 4.72$ mmol), hydrous potassium carbonate $(300 \mathrm{mg}$, $3.03 \mathrm{mmol}$ ) was heated under reflux at $160^{\circ} \mathrm{C}$ for $4 \mathrm{~h}$ under argon atmosphere. 2-bromopyridine was removed by steam distillation. After drying, the copper was filtered with chloroform during heating. The solvent was evaporated under reduced pressure. The residue was purified by column chromatography (toluene-ethyl acetate $(10: 1) /$ silica gel). Recrystallization from methanol afforded 8 (369 $\mathrm{mg}, 0.79 \mathrm{mmol}, 62 \%)$. Purple needles, $\mathrm{mp} 160$ $163{ }^{\circ} \mathrm{C} ; \mathrm{IR}\left(\mathrm{cm}^{-1} / \mathrm{KBr}\right) 3457,2934,1682$ and 1278; ${ }^{1} \mathrm{H} \mathrm{NMR}\left(\mathrm{CDCl}_{3} / \mathrm{TMS}, \delta \mathrm{ppm}\right) 6.70(\mathrm{~d}$, $1 \mathrm{H}), 6.97$ (dd, $2 \mathrm{H}), 7.02-7.15(\mathrm{~m}, 3 \mathrm{H}), 7.20-$ $7.28(\mathrm{~m}, 5 \mathrm{H}), 7.31-7.34(\mathrm{~m}, 1 \mathrm{H}), 7.35-7.43(\mathrm{~m}$, $3 \mathrm{H}), 7.53-7.62(\mathrm{~m}, 2 \mathrm{H}), 7.91(\mathrm{dd}, 1 \mathrm{H})$ and 8.04 (dd, 1H); UV-VIS (nm in ethanol) 494, 350 and 252.

xantheno[ $\left[1^{\prime}, 9^{\prime}: 4,5,6\right]$ benzo $[1,2,3-k l] N-$ (2-pyridyl) acridine (1c). A mixture of 8 (141.5 $\mathrm{mg}, 0.303 \mathrm{mmol}$ ), hydroquinone (140 $\mathrm{mg}, 1.30 \mathrm{mmol})$, sodium chloride $(200 \mathrm{mg}, 3.42$ $\mathrm{mmol})$, anhydrous aluminum chloride $(2.00 \mathrm{~g}$, $15.0 \mathrm{mmol}$ ) was heated under reflux at $160^{\circ} \mathrm{C}$ for $1.5 \mathrm{~h}$. After cooling, $2 \mathrm{~mol} / 1 \mathrm{l}$ hydrochloric acid was added carefully and neutralized by 3 mol/l sodium hydroxide. The resultant was filtered with suction. The residue was washed with a solution of sodium dithionite $(4.00 \mathrm{~g}, 22.0$ $\mathrm{mmol})$ and sodium hydroxide $(2.00 \mathrm{~g}, 0.10$ $\mathrm{mmol})$ in water $(100 \mathrm{ml})$. After washing, the residue was dried in a desiccator for $24 \mathrm{~h}$. The residue was dissolved in toluene and purified by column chromatography (chloroform/silica gel). Recrystallization from toluene afforded 1c (39.5 $\mathrm{mg}, 0.091 \mathrm{mmol}, 30 \%$ ). Purple needles, mp $259^{\circ} \mathrm{C} ; \mathrm{IR}\left(\mathrm{cm}^{-1} / \mathrm{KBr}\right) 2929,1467$ and $1276 ;{ }^{1} \mathrm{H}$ $\mathrm{NMR}\left(\mathrm{CDCl}_{3} / \mathrm{TMS}, \delta \mathrm{ppm}\right) 5.72(\mathrm{~d}, 1 \mathrm{H}), 6.17$ (d, $1 \mathrm{H}), 6.99$ (d, 1H), 7.08 (d, 1H), 7.14-7.25 (m, 4H), 7.37 (t, 2H), 7.66-7.73 (m, 2H), 7.82 (d, $1 \mathrm{H}), 8.03(\mathrm{~d}, 1 \mathrm{H}), 8.12$ (d, 1H), $8.19(\mathrm{~d}, 1 \mathrm{H})$, 8.28 (dd, 1H) and 8.92 (dd, 1H); UV-VIS (nm in ethanol (loge)) $573(3,74), 540(3.70)$ and 422
(3.31); UV-VIS ( $\mathrm{nm}$ in toluene $(\log \varepsilon)$ ) 583 (4.05), 547 (4.01) and 424 (3.61); UV-VIS (nm in chloroform $(\log \varepsilon)) 578(4.30), 543(4.26)$ and 425 (3.87).

xantheno $\left[1^{\prime}, 9^{\prime}: 4,5,6\right]$ benzo $[1,2,3-k l] N-$ (1-methyl-2-pyridyl)acridine iodide (1d). A mixture of 1c $(14.7 \mathrm{mg}, 0.034 \mathrm{mmol})$, iodomethane $(5.37 \mathrm{mg}, 37.8 \mathrm{mmol})$, acetonitrile $(10 \mathrm{ml})$ was heated under reflux at $80^{\circ} \mathrm{C}$ for $7 \mathrm{~h}$ under nitrogen atmosphere. The solvent was removed under reduced pressure. The residue was dissolved in toluene. The resultant were collected by filtration with suction to give 8.9 $\mathrm{mg}(0.015 \mathrm{mmol}, 46 \%)$ of 1d. Purple powder; IR( $\left.\mathrm{cm}^{-1} / \mathrm{KBr}\right) 2921,1458$ and $1267 ;{ }^{1} \mathrm{H} \mathrm{NMR}$ (DMSO, $\delta \mathrm{ppm}) 4.17\left(\mathrm{~s}, 3 \mathrm{H}, \mathrm{CH}_{3}\right), 5.93(\mathrm{~d}, \mathrm{~J}=$ $7.6 \mathrm{~Hz}, 1 \mathrm{H}), 6.42(\mathrm{~d}, \mathrm{~J}=7.9 \mathrm{~Hz}, 1 \mathrm{H}), 7.09(\mathrm{~d}, \mathrm{~J}$ $=7.4 \mathrm{~Hz}, 1 \mathrm{H}), 7.21-7.32(\mathrm{~m}, 5 \mathrm{H}), 7.42-7.50(\mathrm{~m}$, $2 \mathrm{H}), 8.02(\mathrm{~d}, \mathrm{~J}=8.7 \mathrm{~Hz}, 1 \mathrm{H}), 8.11(\mathrm{~d}, \mathrm{~J}=8.7$ $1 \mathrm{H}), 8.18(\mathrm{~d}, \mathrm{~J}=7.8 \mathrm{~Hz}, 1 \mathrm{H}), 8.24(\mathrm{~d}, \mathrm{~J}=7.4$ $\mathrm{Hz}, 1 \mathrm{H}), 8.45(\mathrm{t}, \mathrm{J}=6.9 \mathrm{~Hz}, 1 \mathrm{H}), 8.59(\mathrm{~d}, \mathrm{~J}=7.9$ $\mathrm{Hz}, 1 \mathrm{H}), 9.01(\mathrm{t}, \mathrm{J}=7.9 \mathrm{~Hz}, 1 \mathrm{H})$; UV-VIS (nm in ethanol); 547, 517 and 413; UV-VIS ( $\mathrm{nm}$ in water); 550,521 and 415 .

xantheno[ $\left.1^{\prime}, 9^{\prime}: 4,5,6\right]$ benzo $[1,2,3-k l] N-$ (1-ethyl-2-pyridyl)acridine iodide (1e). A mixture of 1c $(15.5 \mathrm{mg}, 0.036 \mathrm{mmol})$, iodoethane $(6.5 \mathrm{mg}, 41.7 \mathrm{mmol})$, acetonitrile (10 $\mathrm{ml}$ ) was heated under reflux at $80{ }^{\circ} \mathrm{C}$ for $7 \mathrm{~h}$ under nitrogen atmosphere. The solvent was dissolved in toluene. The resultant were collected by filtration with suction to give $7.69 \mathrm{mg}$ $(0.013 \mathrm{mmol}, 37 \%)$ of 1e. Purple powder; ${ }^{1} \mathrm{H}$ NMR (DMSO, $\delta$ ppm) $1.36\left(\mathrm{t}, 3 \mathrm{H}, \mathrm{CH}_{3}\right), 4.47$ (dd, 2H, $\mathrm{CH}_{2}$ ), 5.91 (d, 1H), $6.39(\mathrm{~d}, 1 \mathrm{H}), 7.07$ (d, $1 \mathrm{H}), 7.18-7.32(\mathrm{~m}, 5 \mathrm{H}), 7.40-7.51(\mathrm{~m}, 2 \mathrm{H})$, $7.99(\mathrm{~d}, 1 \mathrm{H}), 8.09$ (d, 1H), $8.19(\mathrm{~d}, 1 \mathrm{H}), 8.25(\mathrm{~d}$, $1 \mathrm{H}), 8.47(\mathrm{t}, 1 \mathrm{H}), 8.60(\mathrm{~d}, 1 \mathrm{H}), 9.00(\mathrm{t}, 1 \mathrm{H})$ and $9.58(\mathrm{~d}, 1 \mathrm{H})$; UV-VIS (nm in ethanol) 573,543 and 422 .

xantheno $\left[1^{\prime}, 9^{\prime}: 4,5,6\right]$ benzo $[1,2,3-k l] N-$ (1-octyl-2-pyridyl)acridine iodide (1f). A mixture of 1c $(17.4 \mathrm{mg}, 0.04 \mathrm{mmol}), 1$ iodooctane (536.5 mg, $2.24 \mathrm{mmol}$ ), potassium iodide (26.5 $\mathrm{mg}, 0.16 \mathrm{mmol}$ ), and acetonitrile $(15 \mathrm{ml})$ was heated under reflux at $80^{\circ} \mathrm{C}$ for 60 $h$ under argon atmosphere. After cooling, the solvent was evaporated under reduced pressure, the resultant was purified by column chromato- 
graphy (chloroform/silica gel and acetone/silica gel). The solvent was evaporated under reduced pressure. Recrystallization from water afford $1 f$ (6.0mg, $8.90 \times 10^{-3} \mathrm{mmol}, 22 \%$ ). Black purple powder, mp 132-140 ${ }^{\circ} \mathrm{C}$ (decomp); IR(cm ${ }^{-}$ $1 / \mathrm{KBr}) 2948,1467$ and $1281 ; \mathrm{MS}$ (FAB) $(\mathrm{m} / \mathrm{z})$ $547\left(\mathrm{M}^{+}-127\right.$, calcd 674, $\left.\mathrm{I}=127\right) ;{ }^{1} \mathrm{H}$ NMR (DMSO/TMS, $\delta \mathrm{ppm}$ ) 0.54-1.24 (m, 11H), 1,54 $(\mathrm{m}, 4 \mathrm{H}), 4.41(\mathrm{t}, 2 \mathrm{H}), 5.99(\mathrm{~d}, 1 \mathrm{H}), 6.45(\mathrm{~d}, 1 \mathrm{H})$, $7.09(\mathrm{~d}, 1 \mathrm{H}), 7.23-7.33(\mathrm{~m}, 5 \mathrm{H}), 7.40-7.52(\mathrm{~m}$, $2 \mathrm{H}), 8.00-8.20(\mathrm{~m}, 4 \mathrm{H}), 8.50(\mathrm{t}, 1 \mathrm{H}), 8.72(\mathrm{~d}$, 1H), $9.06(\mathrm{t}, 1 \mathrm{H})$ and $9.57(\mathrm{~d}, 1 \mathrm{H})$; UV-VIS $(\mathrm{nm}$ in ethanol $(\log \varepsilon)) 546(4.09), 516(4.06)$ and 414 (3.64); UV-VIS ( $\mathrm{nm}$ in toluene $(\log \varepsilon)) 558$ (4.28), $524(4.25)$ and 417 (3.90).

xantheno $\left[1^{\prime}, 9^{\prime}: 4,5,6\right]$ benzo $[1,2,3-k l] N$ (1-decyl-2-pyridyl)acridine iodide (1g). A mixture of $1 \mathrm{c}(21.5 \mathrm{mg}, 0.05 \mathrm{mmol}), 1$ iododecane $(503.0 \mathrm{mg}, 1.85 \mathrm{mmol})$, potassium iodide ( $22 \mathrm{mg}, 0.13 \mathrm{mmol}$ ), and acetonitrile (15 $\mathrm{ml}$ ) was heated under reflux at $80^{\circ} \mathrm{C}$ for $60 \mathrm{~h}$ under argon atmosphere. After cooling, the solvent was evaporated under reduced pressure. The resultant was purified by column chromatography (chloroform/ silica gel and acetone/silica gel). The solvent was evaporated under reduced pressure. Recrystallization from water afforded $1 \mathrm{~g}\left(7.7 \mathrm{mg}, 10.9 \times 10^{-3} \mathrm{mmol}\right.$, $22 \%$ ). Black purple powder, $\mathrm{mp} 125-138{ }^{\circ} \mathrm{C}$ (decomp); IR(cm $\left.{ }^{-1} / \mathrm{KBr}\right) 2958,1462$ and 1286; MS (FAB) (m/z) $575\left(\mathrm{M}^{+}-127\right.$, calcd 702, $\mathrm{I}=127$ ); ${ }^{1} \mathrm{H}$ NMR (DMSO/TMS, $\delta \mathrm{ppm}$ ) 0.65 $1.23(\mathrm{~m}, 11 \mathrm{H}), 1.68-1.74(\mathrm{~m}, 4 \mathrm{H}), 4.38(\mathrm{t}, 2 \mathrm{H})$, $6.00(\mathrm{~d}, 1 \mathrm{H}), 6.44(\mathrm{~d}, 1 \mathrm{H}), 7.08(\mathrm{~d}, 1 \mathrm{H}), 7.20-$ $7.31(\mathrm{~m}, 5 \mathrm{H}), 7.39-7.50(\mathrm{~m}, 2 \mathrm{H}), 7.98-8.18(\mathrm{~m}$, $4 \mathrm{H}), 8.49(\mathrm{t}, 1 \mathrm{H}), 8.72(\mathrm{~d}, 1 \mathrm{H}), 9.05(\mathrm{t}, 1 \mathrm{H})$ and $9.57(\mathrm{~d}, 1 \mathrm{H})$; UV-VIS $(\mathrm{nm}$ in ethanol $(\log \varepsilon))$ 546 (3.66), 516 (3.63) and 414 (3.27); UV-VIS (nm in toluene $(\log \varepsilon)) 557(4.28), 524(4.25)$ and 416 (3.91).

\section{Acknowledgement}

We gratefully thank Mr. Y. Kogo, Nippon Kayaku Co., Ltd., for his useful advice in molecular orbital calculations. We also thank Mr. G. Li, Mr. N. Akaba and Miss T. Sato, Saitama University, for their assistance in carrying out the experiments.
(1996).

2) S. Tokita, T. Watanabe, Y. Fujita, H. Iijima, and S. Terazono, Mol. Cryst. Liq. Cryst., submitted.

3) T. Watanabe, T. Tachikawa, N. Kitahara, and S. Tokita, Mol. Cryst. Liq. Cryst., submitted; Y. Kobayashi, S. Mochizuki, H. Yoshida, K. Nakatsu, T. Arai, T. Ishii, and S. Tokita, Proc. 2nd International Symp. on Chem. of Functional Dyes, Kobe, p. 425 (1992).

4) D. G. Whitten, J. Am. Chem. Soc., 96, 594 (1974).

5) J. Hibino, Kikan Kagaku Sosetsu, 28, 178 (1996); M. Irie, T. Tamaki, T. Seki, and J. Hibino, Photochromic Spiropyrans, Bunshin (1993), Chap. 4, p. 85.

6) T. Seki, R. Fukuda, M. Yokoi, T. Tamaki, and K. Ichimura, Bull. Chem. Soc. Jpn., 69, 2375 (1996).

7) H. Nakahara, J. Jpn. Oil Chem. Soc., 45(10), 1073 (1996); H. Hama, A. Miyashita, K. Yamaoka and H. Nakahara, Chem. Lett., 313 (1996).

8) S. Tokita, "Color Chemistry", Maruzen Co., Tokyo, p.115 (1982).

9) N. L. Allinger, J. Am. Chem. Soc., 99, 8127 (1977).

10) The software on a Macintosh platform was provided by SONY Tektronix Co. Ltd.

11) M. J. S. Dewar, E. G. Zoebisch, E. F. Healy and J. P. Stewart, J. Am. Chem. Soc., 107, 3902 (1985).

12) J. E. Ridley and M. C. Zerner, Theor. Chim Acta., 32, 111 (1973); A. D. Bacov and M. C. Zerner, Theor. Chim Acta., 53, 21 (1979); M. C. Zerner, G. H. Loew, R. F. Kirchner and U. T. Mueller-Westernhoff, J. Am. Chem. Soc., 102, 589 (1980); The authors express our hearty thanks to Professor M. C. Zerner for providing the ZINDO program.

13) G. D. Purvis III, 3rd International Symp. on Chem. of Functional Dyes, Santa Cruz, PL-3 p.24 (1995); S. Tokita, T. Suzuki, T. Shimokoshi, Y. Kogo and K. Kafuku, J. Photopolym. Sci. Technol., 4, 41 (1991); S. Tokita, T. Suzuki and M. Nikaido, J. Photopolym. Sci. Technol., 5, 533 (1992).

14) E. H. Ruediger, M. L. Kaldas, S. S. Gandhi, C. Fedryna and M. S. Gibson, J. Org. Chem., 45, 1974 (1980).

\section{References}

1) S. Tokita, Kikan Kagaku Sosetsu, 28, 135 